\title{
Papers
}

\section{Chlamydia pneumoniae in vitro and in vivo: a critical evaluation of in situ detection methods}

\author{
A Meijer, P J M Roholl, S K Gielis-Proper, Y F Meulenberg, J M Ossewaarde
}

\begin{abstract}
Aims-There is a considerable discrepancy between data from the detection of Chlamydia pneumoniae in atherosclerotic lesions obtained by means of immunocytochemistry and data obtained using the polymerase chain reaction. This study evaluated methods for the in situ detection and assessment of the viability of $C$ pneumoniae bacteria.

Methods-Chlamydia pneumoniae membrane protein, heat shock protein 60 , and lipopolysaccharide were detected by immunocytochemistry, and genomic DNA and $16 \mathrm{~S}$ rRNA by in situ hybridisation in paraffin wax embedded sections of cultured HEp2 cells infected with $C$ pneumoniae and of lungs from mice infected intranasally with $C$ pneumoniae.

Results-Inclusions reactive for all three antigens, DNA, and $16 \mathrm{~S}$ rRNA were seen in infected HEp2 cells, in all positive bronchus and alveolar epithelial cells, and in some of the positive infiltrate cells in the lungs of mice up to seven days after infection. In all alveolar macrophages and in the infiltrate cells positive for antigens only, the staining pattern was granularly dispersed throughout the cytoplasm up to seven days after infection. At 21 days after infection, only this granular staining pattern was seen for antigens in infiltrate cells and macrophages in the alveoli and bronchus associated lymphoid tissue. At this time point, DNA or $16 \mathrm{~S}$ rRNA were detected sporadically, but always as inclusion-like staining.

Conclusions-Because antigens with an inclusion-like staining were detected only together with DNA and 16S rRNA, this type of staining pattern suggested the presence of viable bacteria. Thus, the granular staining pattern of antigens in the absence of staining for DNA and $16 \mathrm{~S}$ is most likely caused by non-viable bacteria. In conclusion, these methods are suitable for the in situ detection of $C$ pneumoniae and the assessment of its viability. (f Clin Pathol 2000;53:904-910)
\end{abstract}

Keywords: Chlamydia pneumoniae; immunocytochemistry; in situ hybridisation; animal model
Chlamydia pneumoniae, an important respiratory pathogen and the third recognised species of the Chlamydiaceae family, has been associated with atherosclerotic vascular diseases. ${ }^{1}$ Initially, this association was observed in seroepidemiological studies. ${ }^{2}$ Subsequently, $C$ pneumoniae has been demonstrated in atherosclerotic lesions of all major arteries by several techniques. ${ }^{3}$ However, discrepancies were noted between the results of culture, immunocytochemistry (ICC), electron microscopy, the polymerase chain reaction (PCR), and in situ hybridisation (ISH). ${ }^{3-7}$ These discrepancies could be explained by the poor sensitivity of $C$ pneumoniae culture methods, sample error, PCR inhibitors, or different avidities of the antibodies used in ICC. Although the detection of $C$ pneumoniae DNA by PCR is important in the study of the role of $C$ pneumoniae in the pathogenesis of atherosclerosis, this technique does not provide information on the location or viability of the microorganism in the diseased tissue. To comply with the molecular guidelines of Fredricks and Relman ${ }^{8}$ for establishing microbial disease causation, confirmation of the presence of $C$ pneumoniae DNA in vessel walls by PCR should be obtained by in situ techniques. So far, ISH for the detection of $C$ pneumoniae DNA in vessel walls has been reported three times, showing variable results. ${ }^{49}$ These studies found that one coronary artery specimen from only one of eight patients with specimens positive in PCR and/or ICC, ${ }^{4}$ none of the abdominal aortic aneurysm specimens of 19 patients positive in ICC but negative in PCR, ${ }^{7}$ and five of eight abdominal aortic aneurysm specimens positive in ICC $^{9}$ were positive in ISH for $C$ pneumoniae. To date, no systematic evaluation of in situ techniques for the detection of $C$ pneumoniae has been reported. Here, we report an evaluation of ICC for the in situ detection of various antigens of $C$ pneumoniae, and of ISH for the in situ detection of DNA and 16S rRNA of $C$ pneumoniae by using well defined specimens from in vitro and in vivo experiments.

\section{Methods}

CHLAMYDIA PNEUMONIAE STRAINS AND INOCULUM PREPARATION

Chlamydia pneumoniae strains TW-183 (Washington Research Foundation (WRF), Seattle, 
Washington, USA) and AR-39 (WRF) were propagated in HEp2 cells (code CCL23; American Type Culture Collection, Manassas, Virginia, USA), as described previously. ${ }^{10}$ Briefly, one day old monolayers in six well microtitre plates were inoculated with $C$ pneumoniae by means of centrifugation (one hour, $25^{\circ} \mathrm{C}, 4800 \times g$ ). The monolayers were incubated for 72 hours at $35^{\circ} \mathrm{C}$ and $5 \% \mathrm{CO}_{2}$ in Iscove's modified Dulbecco's medium (Gibco BRL, Life Technologies, Breda, The Netherlands) supplemented with antibiotics $(100 \mu \mathrm{g} /$ $\mathrm{ml}$ vancomycin, $100 \mu \mathrm{g} / \mathrm{ml}$ streptomycin, and $25 \mathrm{E} / \mathrm{ml}$ nystatin), cycloheximide $(1 \mu \mathrm{g} / \mathrm{ml})$, and $10 \%$ fetal calf serum (chlamydia culture medium). The cells were scraped off the microtitre plates and suspended in culture medium (Iscove's modified Dulbecco's medium supplemented with $10 \%$ fetal calf serum and antibiotics, $100 \mu \mathrm{g} / \mathrm{ml}$ vancomycin, $100 \mu \mathrm{g} /$ $\mathrm{ml}$ streptomycin, and $25 \mathrm{E} / \mathrm{ml}$ nystatin). Then, the bacteria were released from the cells by sonication. Cellular debris was removed by centrifugation for five minutes at $500 \times g$. The suspensions were aliquoted and stored at $-80^{\circ} \mathrm{C}$. One vial was thawed to determine the number of inclusion forming units (IFU) by titration.

IN VITRO EXPERIMENTS

One day old monolayers of HEp2 cells in six well microtitre plates were either infected at a multiplicity of infection (MOI) of 0.1 IFU with $C$ pneumoniae strain TW-183 or mock infected with chlamydia culture medium as described above. Cells infected with $C$ pneumoniae were harvested by trypsinisation at five, 13, 21, 29, 46, and 72 hours after infection, washed once with culture medium, and once with phosphate buffered saline (PBS), then fixed for 24 hours in $10 \%$ buffered formalin. Mock infected cells were harvested at 72 hours after infection only. The fixed cells were washed once with PBS, dehydrated, and embedded in paraffin wax.

IN VIVO EXPERIMENTS

All in vivo experiments were approved by the institutional animal care and animal experiments committee. Four to six week old female C57B6/JIco mice were randomised before infection. Each group was held in a separate incubation box and the animals were given access to food and water ad libitum. Infections were carried out under light ether anaesthesia to induce hyperventilation. One day before infection with $C$ pneumoniae three control mice were mock infected intranasally with supernatant from a mock infected HEp2 cell culture. On the day of infection with $C$ pneumoniae the control mice were sacrificed. Six mice were infected intranasally with $4.3 \times 10^{8} \mathrm{IFU}$ and four mice with $1 \times 10^{6}$ IFU of $C$ pneumoniae strain AR-39 in $50 \mu \mathrm{l}$ culture medium. Of the six mice infected with $4.3 \times 10^{8}$ IFU of $C$ pneumoniae three were sacrificed two days after infection, and three were sacrificed seven days after infection. The mice infected with $1 \times 10^{6}$ IFU of $C$ pneumoniae were sacrificed 21 days after infection. Lungs were removed, intratracheally filled with $10 \%$ buffered forma- lin, fixed for 24 hours in $10 \%$ buffered formalin, and embedded in paraffin wax.

\section{HISTOLOGY AND IMMUNOCYTOCHEMISTRY}

One $4 \mu \mathrm{m}$ paraffin wax section each of HEp2 cells infected with $C$ pneumoniae, mock infected HEp2 cells, the lungs of mice infected with $C$ pneumoniae, and the lungs of mock infected mice was stained with haematoxylin and eosin for histological examination.

Consecutive $4 \mu \mathrm{m}$ paraffin wax sections were used to detect chlamydial antigens by ICC using an indirect immunoperoxidase method, as described previously. ${ }^{7}$ One $C$ pneumoniae species specific antimembrane protein monoclonal antibody RR-402 ${ }^{11}$ (WRF), three chlamydia genus specific antilipopolysaccharide (LPS) monoclonal antibodies (two (16.3B6 and 16.1D10) produced and characterised in our laboratory ${ }^{12}$ and $\mathrm{CF}-2^{13}$ (WRF)), and one chlamydia genus specific anti-heat shock protein 60 (hsp60) monoclonal antibody A57-B9 ${ }^{14}$ (Affinity Bioreagents, SanverTECH, Breda, The Netherlands) were used. Irrelevant primary monoclonal antibodies of the same isotype were used as negative control antibodies.

\section{IN SITU HYBRIDISATION}

The detection of $C$ pneumoniae DNA by in situ DNA hybridisation (ISDH) on $4 \mu \mathrm{m}$ paraffin wax sections adjacent to those stained by ICC was carried out with a digoxigenin (DIG) labelled $C$ pneumoniae major outer membrane protein (MOMP) gene fragment as a probe and with a DIG labelled minute virus of mouse (MVM) genome fragment as a negative control probe, as described previously. ${ }^{7}$

The detection of $C$ pneumoniae $16 \mathrm{~S}$ rRNA by in situ RNA hybridisation (ISRH) in $4 \mu \mathrm{m}$ paraffin wax sections adjacent to those stained with ISDH or ICC was carried out with an antisense $3^{\prime}$ and 5' DIG labelled oligonucleotide probe specific for the order Chlamydiales $16 \mathrm{~S}$ rRNA (5'-ATGTA(T/C)TACTAACCC TTCCGCCACTA-3'), including recently discovered chlamydia-like sequences. ${ }^{15}$ A sense $3^{\prime}$ and 5' DIG labelled oligonucleotide probe (5'TAGTGGCGGAAGGGTTAGTA(G/A)TAC AT-3') was used to assess the specificity of the antisense probe for rRNA. A nonsense 3 ' and 5' DIG labelled oligonucleotide probe composed of the same nucleotides as the antisense probe but in a different sequence (5'-ATCCTAC GCTACTAAGTCTCTCATCA-3') was used as a negative control probe. After dewaxing and proteinase $\mathrm{K}$ treatment $(2.5 \mu \mathrm{g} / \mathrm{ml})$ of the sections as described for ISDH, ${ }^{7}$ the slides were immersed for five minutes at room temperature in $0.2 \%$ glycine in PBS followed by five minutes in $2 \times$ saline sodium phosphate EDTA buffer (SSPE; $1 \times \mathrm{SSPE}$ is $10 \mathrm{mmol} /$ litre $\mathrm{NaPO}_{4}$ containing $180 \mathrm{mmol} /$ litre $\mathrm{NaCl}$ and $1 \mathrm{mmol} /$ litre $\mathrm{Na}_{2} \mathrm{EDTA}$ ) at $95^{\circ} \mathrm{C}$. Next, the slides were immersed in prewarmed hybridisation mixture (2× SSPE containing $100 \mu \mathrm{g} / \mathrm{ml}$ denatured herring sperm DNA and $5.1 \mathrm{pmol} / \mathrm{ml}$ probe) and incubated for 45 minutes at $55^{\circ} \mathrm{C}$. After two washes with $2 \times$ SSPE for 10 minutes at 
$55^{\circ} \mathrm{C}$ the hybridised probes were detected as described for ISDH. ${ }^{7}$

DNAse (Boehringer Mannheim; $1 \mathrm{U} / \mu \mathrm{l}$ in $0.1 \mathrm{mmol} /$ litre $\mathrm{NaAc}(\mathrm{pH} 5.0)$ containing $5 \mathrm{mmol} /$ litre $\mathrm{MgSO}_{4}$ for one hour at $37^{\circ} \mathrm{C}$ ) or RNAse A (Invitrogen BV, Leek, The Netherlands; $100 \mu \mathrm{g} / \mathrm{ml}$ in $2 \times \mathrm{SSC}$ containing $10 \mathrm{mmol} /$ litre $\mathrm{MgCl}_{2}$ for one hour at $37^{\circ} \mathrm{C}$ ) pretreatment of the sections was used to confirm the specificity of the hybridisation reactions.

\section{Results}

IN VITRO EXPERIMENTS

Mock infected cells did not react with the monoclonal antibodies, and cells infected with $C$ pneumoniae did not react with the irrelevant monoclonal antibodies. No hybridisation signal was seen in mock infected cells with the MOMP probe, the antisense $16 \mathrm{~S}$ rRNA probe, or the sense $16 \mathrm{~S}$ rRNA probe. In addition, no hybridisation signal was observed at any point in time after infection in cells infected with $C$ pneumoniae with the MVM probe, the nonsense probe, or the sense $16 \mathrm{~S}$ rRNA probe.

By five hours after infection, $C$ pneumoniae LPS was detected with monoclonal antibody 16.1D10. At 13 hours post infection $C$ pneumoniae DNA was detected with the MOMP probe, and LPS was detected using the monoclonal antibodies 16.1D10 and 16.3B6. From 21 hours post infection onwards, $C$ pneumoniae membrane protein (fig $1 \mathrm{~A}-\mathrm{C}$ ); LPS with monoclonal antibodies 16.1D10, 16.3B6 (fig 1D-F), and CF-2; and DNA and 16S rRNA (fig $1 \mathrm{~J}-\mathrm{L}$ ) were detected. The staining pattern for DNA was similar to that for $16 \mathrm{~S}$ rRNA, as shown in fig 1 . Hsp60 was detected at 29 hours after infection for the first time (fig 1G-I).

Up to 29 hours after infection the observed inclusions were very small (fig $1 \mathrm{~A}, \mathrm{~B}, \mathrm{D}, \mathrm{E}, \mathrm{H}$, $\mathrm{J}$, and $\mathrm{K}$ ). Their size increased at least 10 times at 46 hours after infection. At this point in time, more positive cells became visible in agreement with an MOI of 0.1 (fig $1 \mathrm{C}, \mathrm{F}, \mathrm{I}$, and L). At completion of the developmental cycle at 72 hours after infection, the size of the inclusions was again two to three times larger.

The immunoreactivity of the antimembrane protein and of the anti-hsp60 monoclonal antibodies was similar in size and pattern, and the staining was restricted to clearly recognisable inclusions (fig $1 \mathrm{C}$ and $\mathrm{I}$ ). In addition to inclusions, all three anti-LPS monoclonal antibodies also stained the membranes of many cells without visible inclusions, and numerous vesicle-like structures (fig $1 \mathrm{~F}$ ). This type of staining was seen from 29 hours post infection onwards with monoclonal antibody 16.1D10, and from 46 hours post infection onwards with the other two anti-LPS monoclonal antibodies.

The staining pattern for $C$ pneumoniae DNA and $16 \mathrm{~S}$ rRNA was restricted to inclusions. At 46 hours after infection the inclusions stained with the MOMP DNA probe and the antisense $16 \mathrm{~S}$ rRNA probe (fig 1L) were at least twice as large as those stained with the antimembrane protein (fig 1C) and anti-hsp60 (fig 1I) mono- clonal antibodies, but similar to those stained with the anti-LPS monoclonal antibodies (fig $1 \mathrm{~F})$.

After DNAse pretreatment of sections of cells infected with $C$ pneumoniae, no reaction was observed with the MOMP probe, whereas the inclusions were clearly stained with the antisense $16 \mathrm{~S}$ rRNA probe. After RNAse A pretreatment of these sections, no staining was observed with the antisense $16 \mathrm{~S}$ rRNA probe, whereas the inclusions were clearly stained with the MOMP probe.

\section{IN VIVO EXPERIMENTS}

Histologically, the lungs of mock infected mice were normal. Also, no reaction was seen with any of the monoclonal antibodies and probes. Sections of the lungs of mice infected with $C$ pneumoniae did not stain with the irrelevant antibodies, the MVM probe, the nonsense probe, or the sense $16 \mathrm{~S}$ rRNA probe.

At two days post infection, the lung pathology of the mice was characterised by focal interstitial infiltrates of predominantly polymorphonuclear cells and hyperplasia of bronchus epithelial cells. At seven days post infection, an interstitial pneumonia was observed with focal infiltrates of macrophages only. In addition, polymorphonuclear cells were seen in the alveoli and alveolar macrophages showed vacuolisation. At 21 days post infection, small multifocal periarterial and peribronchial infiltrates of macrophages and lymphocytes were observed. These infiltrates were also located focally in the subpleura. Sometimes, focal infiltrates-predominantly of lymphocytes - were seen in the alveoli. Polymorphonuclear cells were not noted at this time point. Bronchus epithelial cells showed sporadic vacuolisation and blebbing.

Table 1 summarises the cellular distribution pattern of $C$ pneumoniae components in the lungs. At two days post infection, clearly recognisable inclusions positive with all the monoclonal antibodies and the probes were observed in bronchus epithelial cells (fig 2A-C) and in alveolar epithelial cells (fig $2 \mathrm{~A}$ and $\mathrm{E}$ ). In addition, blebs derived from bronchus epithelial cells stained positive for membrane protein and LPS. Many alveolar macrophages showed a vacuolised and granular immunostaining pattern (fig 2D and F), but only some of them showed a hybridisation reaction with the two probes. Viable bacteria were also present in infiltrate cells, as suggested by positive DNA and $16 \mathrm{~S}$ rRNA (fig 2E) hybridisation reactions. These cells were also immunoreactive for LPS (fig 2F), and to a lesser extent for membrane protein, but not for hsp60. At seven days post infection, a lower number of epithelial cells was stained for the various $C$ pneumoniae components. However, a higher number of macrophages in alveoli and in the infiltrates was positive for all three antigens, especially for LPS. In addition to blebs derived from bronchus epithelium, frequently the apical membrane of bronchus epithelial cells was stained for LPS. The cytoplasmic staining pattern of the different cell types was similar to that seen at two days post infection. In addition, macrophages 
in bronchus associated lymphoid tissue (BALT) sporadically stained granularly for all three antigens. At 21 days post infection, no staining for any of the $C$ pneumoniae antigens was observed in epithelial cells, and only a few alveolar macrophages (fig 2I) and infiltrate cells were positive for one or more of the $C$ pneumoniae antigens. However, several macrophages in BALT stained strongly for membrane protein (fig 2G), LPS, and hsp60 (fig $2 \mathrm{H})$. Staining was seen as dots scattered throughout the cytoplasm of positive cells. However, in all the sections examined, viable bacteria were observed only sporadically in epithelial and infiltrate cells, and in macrophages in BALT, as suggested by a positive
ISDH, although no $16 \mathrm{~S}$ rRNA hybridisation reactivity was seen.

\section{Discussion}

We have shown that, in the early stages of the developmental cycle of $C$ pneumoniae in cultured cells, the most sensitive techniques for the in situ detection of $C$ pneumoniae were ICC for chlamydial LPS and ISDH. In the later stages of the developmental cycle the sensitivities of ICC for membrane protein, LPS, and hsp60; and ISDH and ISRH for 16S rRNA were similar. The detection of the antigens in sections of the lungs of mice infected with $C$ pneumoniae showed considerable heterogeneity, depending on the type of cell that was
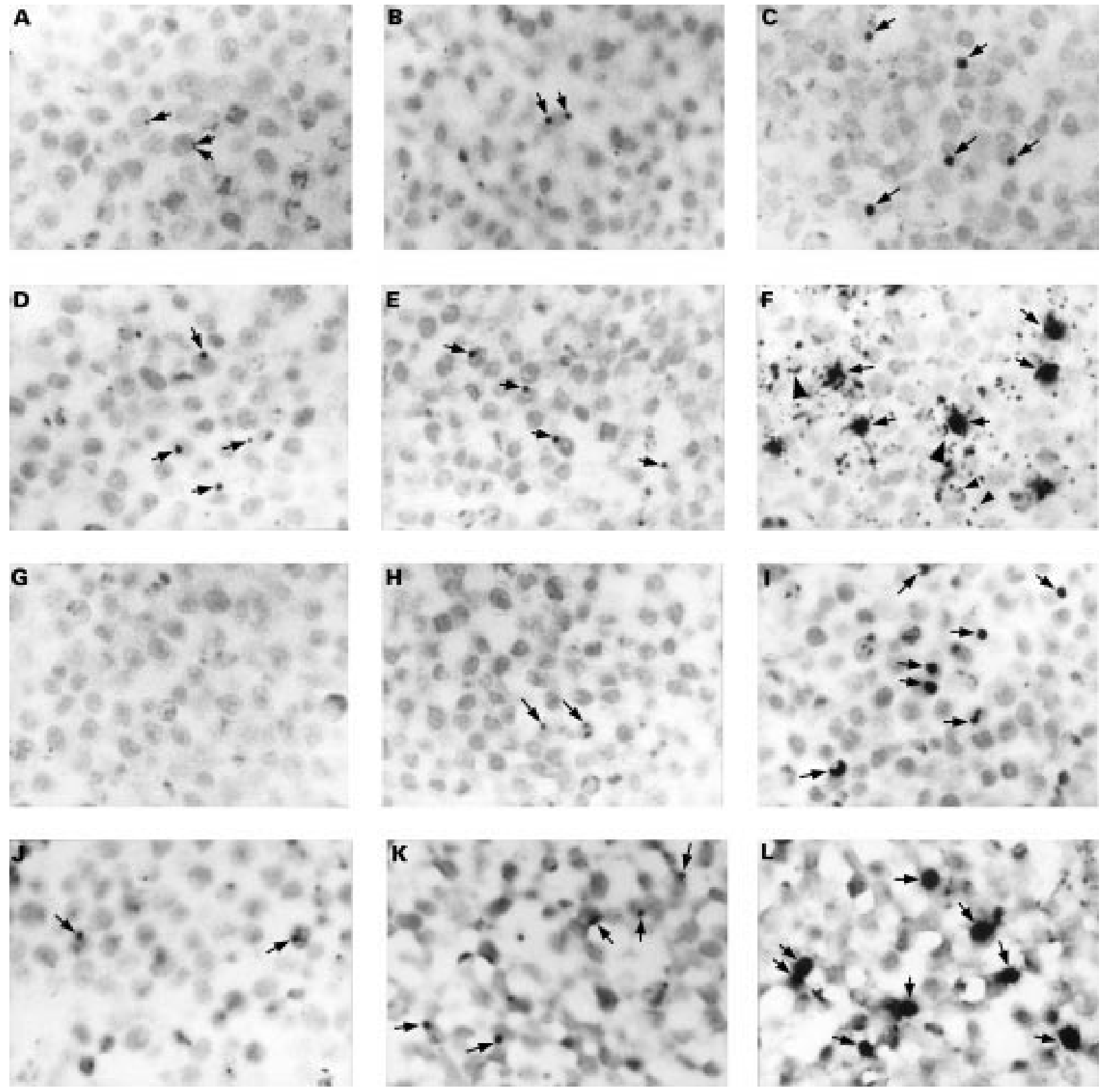

Figure 1 The detection of Chlamydia pneumoniae in paraffin wax embedded sections of formalin fixed HEp2 cells infected with a multiplicity of infection of 0.1 inclusion forming units of $C$ pneumoniae. Cells were fixed at 21 ( $A, D, G$, and 7$), 29(B, E, H$, and $K)$, and 46 (C, F, I, and $L)$ hours after

infection. Sections were immunostained for $C$ pneumoniae membrane protein $(A-C), L P S(D-F$; with monoclonal antibody 16.3B6), or hsp60 ( $G-I)$, or hybridised for $16 S r R N A(\mathcal{F}-L)$. In the early stages of the developmental cycle of $C$ pneumoniae, up to 29 hours post infection, only very small inclusions were seen ( $A, B, D, E, H, \mathcal{F}$, and $K$; arrows). No immunostaining was observed for hsp60 at 21 hours after infection $(G)$. Inclusions were up to 10 times larger at a later stage of the developmental cycle (C,F, I, and L; arrows). Membranes of non-infected cells (F; large arrowheads) and vesicle-like structures (F; small arrowheads) were also immunostained for LPS. Counterstaining, nuclear fast red. Original magnification, $\times 125(A-L)$. 
infected and on the point in time after infection. Overall, viable bacteria, as suggested by a positive $16 \mathrm{~S}$ rRNA hybridisation reaction, were seen in the early stages of infection in bronchus and alveolar epithelial cells, in infiltrate cells, and in alveolar macrophages. In the later stages of infection antigens were seen mainly in alveolar macrophages and macrophages in BALT. Furthermore, in the early stages of infection, clearly defined inclusions could be demonstrated by immunostaining, whereas in the later stages the immunostaining was dispersed throughout the cytoplasm.

A possible explanation for the differences in the detection of $C$ pneumoniae antigens in the early stages of the infection of cultured cells could be the amount of antigen present, because the synthesis and maturation of proteins and lipopolysaccharides are temporally regulated. ${ }^{16}$ By the later stages of infection, when larger numbers of bacteria had produced mature proteins and lipopolysaccharides, all monoclonal antibodies performed equally well. The staining of the membranes of many cells without visible inclusions and numerous vesicle-like structures with the anti-LPS monoclonal antibodies is probably caused by the shedding of LPS. This observation is in agreement with previously reported results for the shedding of Chlamydia trachomatis LPS. ${ }^{17}$ Our results of the detection of $C$ pneumoniae hsp60 in cultured cells with monoclonal antibody A57-B9 are consistent with the results obtained for $C$ trachomatis with the same antibody. ${ }^{14}$

We found that the sensitivity of ISRH was slightly less than that of ISDH, detecting $C$ pneumoniae 21 and 13 hours after infection for the first time, respectively. This point in time corresponds with the beginning of the replication of the bacterium after the conversion of the infectious but metabolically inactive elementary body into the non-infectious but metabolically active reticulate body. ${ }^{16}$ However, the number of copies of rRNA present in one bacterium is much higher than that of genomic DNA. Thus, it is probable that the difference in sensitivity is related to the number of DIG labels for each probe. The sensitivity of ISRH for the detection of $C$ pneumoniae can be increased by using a larger probe or by the incorporation of more labels. ${ }^{18-22}$ However, the $16 \mathrm{~S}$ rRNA antisense probe was designed to detect all members of the order Chlamydiales, including the chlamydia-like organisms, ${ }^{15} \mathrm{im}$ posing restrictions on the length of this probe. In addition, an RNA directed probe was chosen because the detection of 16S rRNA provides information on the metabolic activity of the bacterium. Chlamydial elementary bodies contain mainly $4 \mathrm{~S}$ rRNA, whereas the reticulate bodies consist predominantly of $21 \mathrm{~S}$, $16 \mathrm{~S}$, and $4 \mathrm{~S}$ rRNA, in much higher quantities. $^{16}$

The lung pathology of the mice infected with $C$ pneumoniae was similar to that reported previously. ${ }^{2324}$ In both of these earlier studies, the lung pathology was also characterised by patchy interstitial pneumonitis, with predominantly polymorphonuclear cell infiltration in the early stages of infection and mononuclear cell infiltration in the later stages.

Clearly recognisable inclusions were seen only in the early stages of infection in bronchus and alveolar epithelial cells that were positive for $C$ pneumoniae membrane protein, LPS, hsp60, DNA, and 16S rRNA, suggesting active replication. This finding is in agreement with the frequently observed inclusions in bronchus epithelial cells in the early stages of the infection by electron microscopy, as reported previously. ${ }^{25}$ However, in the later stages of infection no clearly recognisable inclusions were seen in any type of cell positive for $C$ pneumoniae antigens, and hybridisation was positive only very sporadically, suggesting only limited replication of $C$ pneumoniae. In addition, the staining pattern for the antigens was granularly dispersed throughout the cytoplasm. These observations suggest the persistence and/or accumulation of antigens in cells, but not the persistence of viable bacteria. Because most of the positive cells at the later stages of infection were macrophages, the accumulation of the phagocytosed remnants of infected cells is likely. However, $C$ pneumoniae

Table 1 Cellular distribution pattern of Chlamydia pneumoniae components at different times after infection in the lungs of mice infected intranasally with C pneumoniae

\begin{tabular}{|c|c|c|c|c|c|c|}
\hline \multirow[b]{2}{*}{ Type of cells } & \multirow[b]{2}{*}{$\begin{array}{l}\text { Days post } \\
\text { infection }\end{array}$} & \multirow[b]{2}{*}{$\begin{array}{l}\text { C pneumoniae DNA } \\
\text { and } 16 S \text { rRNA }\end{array}$} & \multicolumn{4}{|c|}{ C pneumoniae antigens } \\
\hline & & & $\begin{array}{l}\text { Membrane } \\
\text { protein }\end{array}$ & $\begin{array}{l}\text { Lipopoly- } \\
\text { saccharide }\end{array}$ & $\begin{array}{l}\text { Heat shock } \\
\text { protein } 60\end{array}$ & $\begin{array}{l}\text { Staining } \\
\text { pattern }\end{array}$ \\
\hline \multirow[t]{3}{*}{ Bronchus and alveolar epithelium } & 2 & ++ & ++ & ++ & + & I \\
\hline & 7 & ND & + & + & + & \\
\hline & 21 & \pm & - & - & - & NA \\
\hline \multirow[t]{3}{*}{ Alveolar macrophages } & 2 & + & ++ & ++ & ++ & $\mathrm{G}$ \\
\hline & 7 & ND & + & +++ & ++ & G \\
\hline & 21 & - & + & + & \pm & $\mathrm{G}$ \\
\hline \multirow[t]{3}{*}{ Infiltrate cells } & 2 & ++ & \pm & ++ & - & I and $G$ \\
\hline & 7 & ND & ++ & ++ & + & $\mathrm{I}$ and $\mathrm{G}$ \\
\hline & 21 & \pm & $+/-$ & - & + & G \\
\hline \multirow[t]{3}{*}{ Macrophages in bronchus associated lymphoid tissue } & 2 & $\stackrel{\perp}{-}$ & - & - & - & NA \\
\hline & 7 & ND & \pm & \pm & \pm & $\mathrm{G}$ \\
\hline & 21 & \pm & + & + & + & $\mathrm{G}$ \\
\hline
\end{tabular}

The results are the combined results of three mice at two days, three mice at seven days, and four mice at 21 days after infection. All mice at the same time point after infection showed a similar staining pattern.

Chlamydia pneumoniae DNA and 16S rRNA were determined by in situ hybridisation; the staining pattern was always inclusion-like.

Chlamydia pneumoniae antigens were determined by immunocytochemistry.

Number of positive cells graded: - , none;,$\pm<5 /$ section; +, 5-25/section;,$++ 26-100 /$ section;,$+++>100 /$ section; ND, not done.

Staining patern: G, granular; I, inclusion-like; NA, not applicable. 

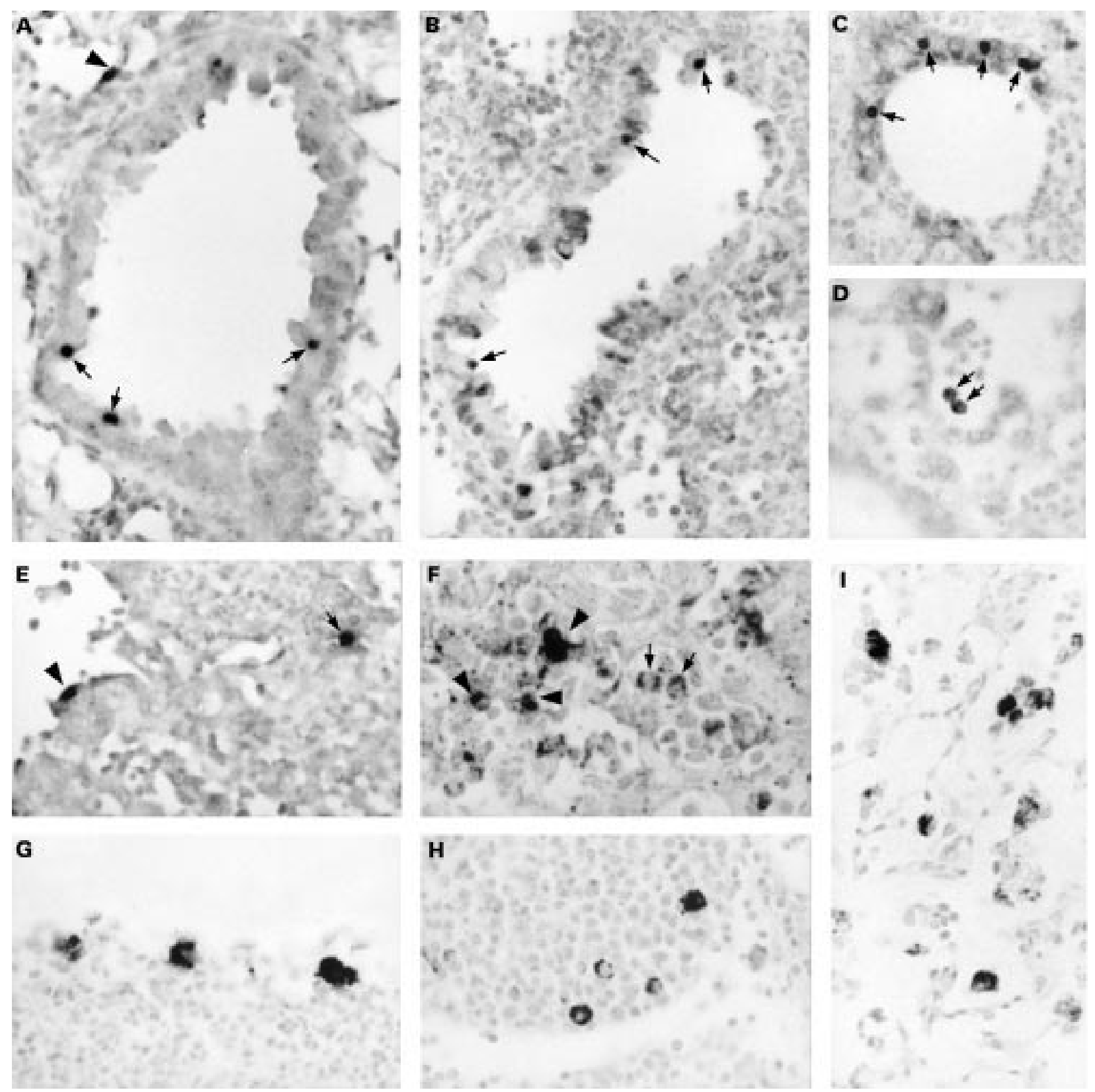

Figure 2 The detection of Chlamydia pneumoniae in paraffin wax embedded sections of formalin fixed lungs of mice intranasally infected with $C$ pneumoniae. Results are from mice sacrificed at two $(A-F)$ and 21 ( $G-I)$ days after infection. Sections were immunostained for membrane protein (G), lipopolysaccharide (B, F, and I; with monoclonal antibody 16.3B6), or hsp60 (C, D, and H), or hybridised for DNA (A) or 16S rRNA (E). In the early stages of infection, clearly recognisable inclusions were observed in bronchus epithelial cells ( $A-C$; arrows) and in alveolar epithelial cells ( $A$ and $E$; arrowhead). Alveolar macrophages showed a vacuolised immunostaining pattern ( $D$ and F; arrows). Infiltrate cells were positive by immunostaining (F; arrowheads) and by in situ hybridisation ( $E$; arrow). In the later stages of infection, macrophages in bronchus associated lymphoid tissue ( $G$ and $H)$ and alveolar macrophages (I) showed a granular immunostaining pattern dispersed throughout their cytoplasm. Counterstaining, nuclear fast red. Original magnification, $\times 125(A-I)$.

can also replicate in these cells, as indicated by a positive hybridisation reaction in some infiltrate cells and BALT macrophages, in agreement with the replication of $C$ pneumoniae in cultured macrophages. ${ }^{26}$ Furthermore, the appearance of antigen positive cells in BALT in the later stages of infection is consistent with the function of macrophages: to present antigens phagocytosed elsewhere in the lung to lymphocytes in BALT to induce an immune reaction. ${ }^{27}$ The granular immunoreactivity pattern of the antigens highly resembled the staining pattern seen previously in human abdominal aortic aneurysm specimens that were negative by ISDH also. ${ }^{7}$ We conclude that this pattern of staining of antigens and the negative reactions in ISDH and ISRH suggest the presence of non-viable $C$ pneumoniae.

In contrast to the presence of membrane protein and LPS in epithelial cells in the early stages of infection, hsp60 was present in very low amounts. Because the presence of DNA and $16 \mathrm{~S}$ rRNA indicated replication, hsp60 values were probably close to the detection limit. Previously, in vitro studies with $C$ trachomatis showed that hsp60 is expressed constitutively under normal culture conditions and the addition of interferon $\gamma$ results in its upregula- 
tion. ${ }^{28}$ However, it is not clear if these results can be extrapolated to in vivo conditions. Hsp60 was present more abundantly in macrophages in the later stages of infection than in the early stages. This can most likely be explained by the accumulation of hsp60 as a result of the phagocytosis of remnants of infected cells, because these macrophages were negative in ISDH and ISRH. Because of the absence of evidence for the presence of viable bacteria in these macrophages, the upregulation of hsp60 expression as a result of local factors is less likely.

In conclusion, ICC for the detection of membrane protein, hsp60, and LPS; and ISDH and ISRH for $16 \mathrm{~S}$ rRNA are suitable techniques to demonstrate the presence of $C$ pneumoniae in formalin fixed tissues. In addition, infection and antigen persistence can be discriminated from each other by a combination of ICC, ISDH, and ISRH. Previously, we demonstrated that cells that stain positively for $C$ pneumoniae antigens in abdominal aortic aneurysm specimens are negative in ISDH. ${ }^{7}$ Our present results from the in vivo experiments support our hypothesis that $C$ pneumoniae antigens persist in these cells, rather than viable bacteria.

We thank G van Amerongen and C Moolenbeek for technical assistance, and E Rozendal for photographic assistance.

1 Kuo CC, Jackson LA, Campbell LA, et al. Chlamydia pneumoniae (TWAR). Clin Microbiol Rev 1995;8:451-61.

2 Saikku P, Leinonen M, Mattila K, et al. Serological evidence of an association of a novel chlamydia, TWAR, with chronic coronary heart disease and acute myocardial infarction. Lancet 1988;2:983-6.

3 Stille W, Dittmann R, Just-Nübling G. Atherosclerosis due to chronic arteritis caused by Chlamydia pneumoniae: a tentative hypothesis. Infection 1997;25:281-4

4 Ramirez JA, The Chlamydia pneumoniae/atherosclerosis study group. Isolation of Chlamydia pneumoniae from the coronary artery of a patient with coronary atherosclerosis. Ann Intern Med 1996;125:979-82.

5 Grayston JT, Kuo CC, Coulson AS, et al. Chlamydia pneumoniae (TWAR) in atherosclerosis of the carotid artery. Circulation 1995;92:3397-400.

6 Jackson LA, Campbell LA, Kuo CC, et al. Isolation of Chlamydia pneumoniae from a carotid endarterectomy specimen. F Infect Dis 1997;176:292-5.

7 Meijer A, van der Vliet JA, Roholl PJM, et al. Chlamydia pneumoniae in abdominal aortic aneurysms. Abundance of membrane components in the absence of heat shock membrane components in the absence of heat shock protein 60 and

8 Fredricks DN, Relman DA. Sequence-based identification of microbial pathogens: a reconsideration of Koch's postulates. Clin Microbiol Rev 1996;9:18-33.
9 Alakäkarppä H, Surcel H-M, Laitinen K, et al. Detection of Chlamydia pneumoniae by colorimetric in situ hybridization. APMIS 1999;107:451-4.

10 Meijer A, Vallinga CE, Ossewaarde JM. A microcarrier culture method for production of large quantities viable Chlamydia pneumoniae. Applied Microbiology and Biotechnology 1996;46:132-7.

11 Puolakkainen $M$, Parker J, Kuo CC, et al. Further characterization of Chlamydia pneumoniae specific monoclonal antibodies. Microbiol Immunol 1995;39:551-4.

12 Ossewaarde JM, Manten JW, Hooft HJ, et al. An enzyme immunoassay to detect specific antibodies to protein and lipopolysaccharide antigens of Chlamydia trachomatis. 7 Immunol Methods 1989;123:293-8.

13 Swanson AF, Kuo CC. Evidence that the major outer membrane protein of Chlamydia trachomatis is glycosylated. Infect Immun 1991;59:2120-5.

14 Yuan Y, Lyng K, Zhang YX, et al. Monoclonal antibodies define genus-specific, species-specific, and cross-reactive epitopes of the chlamydial 60-kilodalton heat shock protein (hsp60): specific immunodetection and purification of chlamydial hsp60. Infect Immun 1992;60:2288-96.

15 Ossewaarde JM, Meijer A. Molecular evidence for the existence of additional members of the order Chlamydiales. Microbiology 1999;145:411-17.

16 Moulder JW. Interaction of Chlamydiae and host cells in vitro. Microbiol Rev 1991;55:143-90.

17 Campbell S, Richmond SJ, Yates PS, et al. Lipopolysacchaide in cells infected by Chlamydia trachomatis. Microbiology 1994;140:1995-2002.

18 Dutilh B, Bébéar C, Taylor-Robinson D, et al. Detection of Chlamydia trachomatis by in situ hybridization with sulphonated total DNA. Ann Inst Pasteur Microbiol 1988;139:115-28.

19 Meddens MJM, Quint WGV, van der Willigen $\mathrm{H}$, et al. Detection of Chlamydia trachomatis in culture and urogenital smears by in situ DNA hybridization using a biotinylated DNA probe. Mol Cell Probes 1988;2:261-8.

20 Beutler AM, Schumacher HR, Whittum-Hudson JA, et al. Case report: in situ hybridization for detection of inapparent infection with Chlamydia trachomatis in synovial tissue of a patient with Reiter's syndrome. Am $7 \mathrm{Med} S \mathrm{Sci}$ 1995:310:206-13.

21 Theil D, Hoop R, Herring AJ, et al. Detection of Chlamydia in formalin-fixed and paraffin-embedded avian tissue by in situ hybridization. A comparison between in situ hybridization and peroxidase-antiperoxidase labeling. $f$ Vet $\mathrm{Med} B$ Infect Dis Vet Public Health 1996;43:365-70.

22 Radinsky R, Bucana CD, Ellis LM, et al. A rapid colorometric in situ messenger RNA hybridization technique for analysis of epidermal growth factor receptor in paraffinembedded surgical specimens of human carcinomas. Cancer Res 1993;53:937-43.

23 Yang ZP, Kuo CC, Grayston JT. A mouse model of Chlamydia pneumoniae strain TWAR pneumonitis. Infect Immun 1993;61:2037-40.

24 Moazed TC, Kuo CC, Grayston JT, et al. Murine models of Chlamydia pneumoniae infection and atherosclerosis. $f$ Infect Dis 1997;175:883-90.

25 Yang ZP, Cummings PK, Patton DL, et al. Ultrastructural ung pathology of experimental Chlamydia pneumoniae pneumonitis in mice. F Infect Dis 1994;170:464-7.

26 Gaydos CA, Summersgill JT, Sahney NN, et al. Replication of Chlamydia pneumoniae in vitro in human macrophages, endothelial cells, and aortic artery smooth muscle cells. Infect Immun 1996;64:1614-20.

27 Sminia T, van der Brugge-Gamelkoorn GJ, Jeurissen SH. Structure and function of bronchus-associated lymphoid tissue (BALT). Crit Rev Immunol 1989;9:119-50.

28 Beatty WL, Byrne GI, Morrison RP. Morphologic and antigenic characterization of interferon $\gamma$-mediated persistent Chlamydia trachomatis infection in vitro. Proc Natl Acad Sci U S A 1993;90:3998-4002. 